\title{
FORMULASI HARD CANDY DARI SARI BUAH JERUK NIPIS (Citrus aurantifolio), MADU (Mell depuratum) DAN KAYU MANIS (Cinnamomum burmanii) BERDASARKAN PERBEDAAN SIRUP GLUKOSA
}

\author{
Mega Yulia ${ }^{1}$, Fadhilla Putri Azra ${ }^{2}$, Riki Ranova ${ }^{3}$ \\ 1,2,3 Akademi Farmasi Imam Bonjol \\ Email Korespondensi : megayuriano@yahoo.com.sg
}

\begin{abstract}
ABSTRAK
Jeruk nipis merupakan bahan alam yang banyak digunakan masyarakat untuk pengobatan batuk. Untuk efisiensi dalam penggunaan jeruk nipis dapat dilakukan dengan mengolahnya menjadi suatu produk yang mudah digunakan seperti permen keras. Penelitian ini bertujuan untuk mengetahui hasil uji fisik dan kesukaan panelis terhadap permen keras dari sari buah jeruk nipis, madu dan kayu manis yang dihasilkan. Metode yang digunakan merupakan metode eksperimental dengan mengkombinasikan sari jeruk nipis, madu, kayu manis serta memvariasikan sirup glukosa sebagai bahan pembentuk permen. Evaluasi fisik terhadap masing-masing formula yang meliputi uji kadar air dan kadar abu, serta uji hedonik dari 3 formula terhadap 100 panelis. Hasil evaluasi fisik yang dilakukan terhadap 3 formula diketahui semua formula memenuhi persyaratan mutu permen keras untuk kadar air dan kadar abu sesuai SNI 3547.1:2008 dan hasil uji hedonik menggunakan SPSS non parametrik didapatkan hasil ada pengaruh signifikan terhadap rasa dan tekstur serta formula III yang paling banyak disukai.
\end{abstract}

Kata kunci : Formulasi, hard candy, Jeruk nipis, Madu 


\title{
FORMULATION HARD CANDY FROM LIME (Citrus aurantifolio), HONEY (Mell depuratum) AND CINNAMON (Cinnamomum burmanii) BASED ON DIFFERENT OF GLUCOSE SYRUP
}

\begin{abstract}
Lime is a fruit that is widely used by people for treatment cough. For efficiency use of lime, it can processing to product that easier for using such as hard candy. This study aims to determine the results of physical tests and panelists preference for hard candies made from lime juice, honey and cinnamon. The method used is an experimental method by combining lime juice, honey, cinnamon and varying glucose syrup as a candy forming ingredient. Physical evaluation of each formula which includes analysis of water content and ash content, also hedonic test of 3 formulas to 100 panelists. The results of the physical evaluation carried out on the 3 formulas showed that all formulas met the quality requirements of SNI 3547.1:2008 hard candy for water content and ash content, also the results of the hedonic test using non parametric SPSS showed that there was a significant effect on taste and texture where formula III was the most preferred by panelist.
\end{abstract}

Keywords: Formulation, Hard candy, Lime, Honey

PENDAHULUAN

Permen merupakan produk pangan yang digemari semua kalangan, tidak hanya kalangan anak-anak saja tetapi permen juga disukai oleh kalangan dewasa dan tua. Salah satu jenis permen yang banyak beredar dipasaran saat ini adalah permen keras (hard candy). Permen keras merupakan permen yang memiliki tekstur keras, penampakan mengkilat dan bening (Lawrence, 1991). Bahan baku utama dalam pembuatan permen keras (hard candy) adalah sukrosa, sirup glukosa, dan air (Ramadhan, 2012).

Komponen perasa penting dalam pembuatan permen. Perasa merupakan zat tambahan pada makanan yang dapat memberikan bau dan rasa (Nurwati, 2011). Perasa yang digunakan dapat berupa alami atau sintetik. Namun seiring dengan banyaknya indikasi yang menunjukan bahwa bahan sintetik dapat membahayakan kesehatan, maka kesadaran kembali ke bahan alam menjadi pilihan masyarakat (Yumas, 
2010). Diantara bahan alam yang bermanfaat bagi kesehatan adalah jeruk nipis, madu, dan kayu manis. Jeruk nipis (Citrus aurantifolia) salah satu jenis tanaman yang banyak tumbuh dan dikembangkan di Indonesia. Jeruk nipis bermanfaat untuk obat batuk, peluruh dahak, dan influenza. Jeruk nipis mengandung senyawa kimia yang bermanfaat, seperti asam sitrat, asam amino, minyak atsiri, glikosida, asam sitrun, lemak, kalsium, 2 fosfor, besi, vitamin C dan vitamin B1 (Lauma dkk, 2015). Jeruk nipis selain bermanfaat bagi kesehatan juga dapat sebagai pemberi rasa asam dan sebagai penyegar (Hamidi dkk, 2016).

Madu adalah cairan alami yang umumnya mempunyai rasa manis yang dihasilkan oleh lebah madu dari sari bunga tanaman (floral nektar) atau bagian lain dari tanaman (ekstrak floral nektar) atau ekskresi serangga (Gebremariam and Brhane, 2014). Karena rasa manis yang dimilikinya madu seringkali digunakan sebagai pengganti gula. Madu memiliki manfaat bagi kesehatan diantaranya sebagai antioksidan, mengobati batuk, penyakit lambung, konstipasi, radang usus, jantung, hipertensi, penyakit paru, sakit kepala, sariawan, dan infeksi saluran kemih (Suranto, 2004). Madu juga dimanfaatkan untuk industri makanan, industri minuman, industri farmasi, industri jamu, dan industri kosmetik. Madu mengandung berbagai komponen seperti karbohidrat, asam amino, mineral, enzim, vitamin dan air (Apriani dkk, 2013).

\section{Kulit Kayu manis (Cinnamomum} burmannii) merupakan rempah-rempah yang memiliki nilai tinggi karena kandungan oleoresinnya banyak digunakan untuk penambah aroma produk makanan seperti kue dan produk gula-gula (Jay, 1996). Kulit kayu manis bisa digunakan untuk obat batuk, obat sariawan, sesak napas, nyeri lambung dan juga sebagai anti kanker (Herdwiani dkk, 2009). Kandungan yang terdapat pada kulit kayu manis diantaranya minyak atsiri, safrol, sinamaldehid, eugenol, tanin, flavonoid, dan saponin (Herdwiani dan Endang, 2015). Berdasarkan uraian tersebut maka dilakukan penelitian untuk membuat hard candy dengan mengkombinasikan sari buah jeruk nipis, madu dan kayu manis dengan variasi sirup glukosa sehingga diharapkan dapat menjadi alternatif efisien dalam mengkonsumsi bahan alami tersebut yang biasa 
dikonsumsi masyarakat untuk mengatasi batuk.

\section{METODE PENELITIAN}

Penelitian ini dilakukan dari bulan Februari sampai Juni 2021. Penelitian ini adalah penelitian eksperimental yang bertujuan untuk mengetahui hasil uji fisik dan untuk mengetahui formula hard candy yang disukai panelis berdasarkan perbedaan kandungan sirup glukosa. Formula dibuat sebanyak 3 formula dengan memvariasikan jumlah sirup glukosa. Formula dapat dilihat dari tabel dibawah.

Tabel I. Formulasi hard candy Sari Buah Jeuk Nipis, Madu dan Kayu Manis

\begin{tabular}{lccc}
\hline \multicolumn{1}{c}{ SAMPEL } & FI & FII & FIII \\
\hline Jeruk nipis & $150 \mathrm{ml}$ & $150 \mathrm{ml}$ & $150 \mathrm{ml}$ \\
Madu & $300 \mathrm{ml}$ & $300 \mathrm{ml}$ & $300 \mathrm{ml}$ \\
Serbuk kayu manis & $7,5 \mathrm{gram}$ & $7,5 \mathrm{gram}$ & $7,5 \mathrm{gram}$ \\
Sirup glukosa & $37,5 \mathrm{ml}$ & $75 \mathrm{ml}$ & $112,5 \mathrm{ml}$ \\
\hline
\end{tabular}

Uji Kadar Air

Permen yang dihasilkan dilakukan pengujian kadar air dengan cara, cawanporselen dikeringkan dalam oven pada suhu $105^{\circ} \mathrm{C}$ selama 30 menit, kemudian didinginkan dalam desikator lalu ditimbang berat cawan tersebut. Timbang 2-3 gram hard candy dan dimasukkan ke dalam cawan. Selanjutnya dikeringkan lagi dalam oven pada suhu $100-105^{\circ} \mathrm{C}$ selama 3 jam, lalu didinginakan dalam desikator sampai suhu ruangan dan ditimbang. Bahan kemudian dikeringkan lagi dalam oven selama 1 jam lalu didinginkan dalam desikator kemudian ditimbang. Perlakuan ini diulangi sampai tercapai berat konstan. Perhitungan kadar air dilakukan dengan rumus 


\section{$\underline{\mathrm{Wa}-\mathrm{Wb}} \times 100 \%$}

W

Keterangan : $\quad \mathrm{W}=$ Bobot Permen awal $(\mathrm{g})$

$\mathrm{Wa}=$ Bobot wadah + permen sebelum pemanasan $(\mathrm{g})$

$\mathrm{Wb}=$ Bobot wadah + permen setelah pemanasan $(\mathrm{g})$

\section{Uji Kadar Abu}

Permen yang dihasilkan dilakukan pengujian kadar abu dengan cara cawan porselen dikeringkan dalam oven pada suhu $105^{\circ} \mathrm{C}$ selama 30 menit, kemudian didinginkan dalam desikator lalu ditimbang berat cawan tersebut. Timbang 2-3 gram hard candy dan dimasukkan ke dalam cawan. Panaskan cawan yang berisi sampel di hotplate sampai $\mathrm{H}_{2} \mathrm{O}$ hilang. Kemudian masukkan kedalam tanur pada suhu $500^{\circ} \mathrm{C}$ selama 6 jam sampai diperoleh abu bewarna keputih-putihan, lalu dinginkan dalam desikator dan timbang berat abu setelah dingin. Perhitungan kadar abu dilakukan dengan rumus :

\section{Berat abu $\times 100 \%$ \\ Berat awal}

Keterangan :

Berat abu $=$ berat akhir - berat kurs (gram)

Berat awal $=$ berat sampel awal (gram)

\section{Uji Organoleptik Hard Candy Skala}

\section{Hedonik}

Hard Candy dibagikan kepada

100 orang panelis. Panelis diminta tanggapan kesukaan terhadap aroma, rasa dan tekstur dari hard candy. Panelis diminta untuk mencicipi setiap formula dengan memberikan penetral air putih setiap selesai memakan satu buah permen agar tidak mempengaruhi rasa terhadap permen yang diujikan. Kemudian panelis diminta untuk memberikan tanggapan terhadap masing- masing formula dengan mengisi kuisioner yang telah disediakan. Uji organoleptik skala hedonik yang dilakukan dengan skor kesukaan terhadap formula yang telah dibuat. Skala yang digunakan adalah skala kategorik yang direntangkan dari skala 1 sampai 7 yang 
mempersentasikan tingkat kesukaan panelis dari sangat tidak suka hingga sangat suka (Setyaningsih, 2010).

\section{HASIL DAN PEMBAHASAN}

\section{Pembuatan Hard Candy}

Jeruk nipis sebanyak $2 \mathrm{~kg}$ diperas hingga didapatkan sarinya sebanyak $600 \mathrm{ml}$. Tiap masing-masing formula sari jeruk nipis digunakan $150 \mathrm{ml}$, madu sebanyak $300 \mathrm{ml}$, kulit kayu manis sebanyak 7,5 gram. Jeruk nipis, madu dan kayu manis digunakan karena ketiganya secara empiris dipercaya dapat mengobati batuk (Lauma dkk, 2015; Suranto, 2004;
Herdwiani dkk, 2009). Sedangkan sirup glukosa yang digunakan dibedakan menjadi 3 variasi yaitu untuk formula I digunakan sebanyak $37,5 \mathrm{ml}$, formula II sebanyak $75 \mathrm{ml}$, formula III sebanyak $112,5 \mathrm{ml}$. Sirup glukosa dapat memberikan tekstur yang keras dan mencegah terbentuknya kristal gula. Hal ini serupa dengan penelitian (Pujilestari dan Irnawati, 2017) yang menyatakan semakin menurun kadar glukosa maka kekerasan permen juga semakin menurun. Hasil pembuatan hard candy dapat dilihat pada gambar 1 .

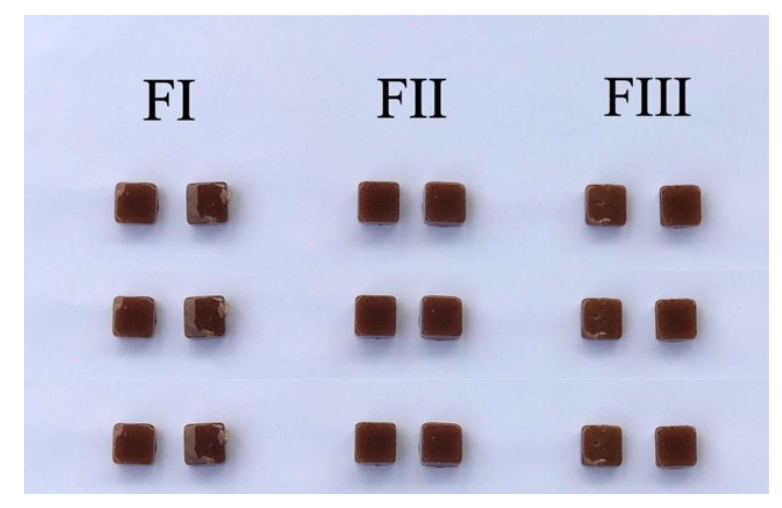

Gambar 1. Hard candy sari buah jeruk nipis, madu dan kayu manis 


\section{Uji Kadar Air}

Tabel 2. Hasil uji kadar air

\begin{tabular}{cccc}
\hline & \multicolumn{3}{c}{ Kadar air } \\
\cline { 2 - 4 } No & FI & FII & FIII \\
\hline 1 & $1,16 \%$ & $0,28 \%$ & $0,21 \%$ \\
2 & $0,82 \%$ & $0,42 \%$ & $0,22 \%$ \\
3 & $0,30 \%$ & $0,29 \%$ & $0,26 \%$ \\
Rata- rata & $0,76 \%$ & $0,42 \%$ & $0,29 \%$
\end{tabular}

Pengujian kadar air permen

memenuhi syarat mutu. Dari hasil ratadilakukan untuk mengetahui rata kadar air memperlihatkan bahwa kandungan air dalam permen. Kadar air sangat berpengaruh terhadap mutu dari semakin banyak penambahan sirup glukosa maka persentasi kadar air permen dan keawetan permen. Permen semakin menurun, hal ini disebabkan jeruk nipis menghasilkan kadar air karena glukosa memiliki gugus untuk formula I sebesar $0,72 \%$, formula hidroksil. Gugus hidroksil ini berfungsi II sebesar $0,42 \%$ dan formula III mengikat air bebas yang berada di luar sebesar 0,29\%. Berdasarkan SNI dan membentuk ikatan air (Nelwan, 3547.1:2008 tentang kembang gula 2014).

keras, kadar air maksimal adalah 3,5\% maka kadar air dari permen jeruk nipis

\section{Uji Kadar Abu}

Tabel 3. Hasil uji kadar abu

\begin{tabular}{cccc}
\hline & \multicolumn{3}{c}{ Kadar abu } \\
\cline { 2 - 4 } No & FI & FII & FIII \\
\hline 1 & $1.47 \%$ & $0,02 \%$ & $0,60 \%$ \\
2 & $0,013 \%$ & $0,61 \%$ & $0,05 \%$
\end{tabular}




$\begin{array}{crrr}3 & 0,065 \% & 0.18 \% & 0,12 \% \\ \text { Rata- rata } & 0,51 \% & 0,27 \% & 0,26 \%\end{array}$

Kadar abu merupakan campuran dari komponen anorganik atau mineral yang terdapat pada suatu bahan pangan. Bahan organik dalam proses pembakaran akan terbakar tetapi komponen anorganiknya tidak, karena itulah disebut dengan kadar abu. Kandungan abu dan komposisinya tergantung pada macam bahan dan cara pengabuannya (Feringo, 2019). Kadar abu merupakan salah satu parameter penentu mutu dari permen, dimana kadar abu ini mempengaruhi penampakan dari permen. Semakin rendah kandungan abu maka penampakan permen akan semakin baik (Mendei, 2014). Dari hasil evaluasi kadar abu permen jeruk nipis menghasilkan kadarabu untuk formula I sebesar $0,51 \%$, formula II sebesar, $0,27 \%$ dan formula III sebesar $0,26 \%$. Berdasarkan SNI 3547.1:2008 tentang kembang gula keras, kadar abu maksimal adalah $2 \%$ maka kadar abu dari permen jeruk nipis memenuhi syarat mutu SNI.

Uji Organoleptik Hard Candy Skala

\section{Hedonik}

Uji hedonik dilakukan dengan menggunakan panelis konsumen sebanyak 100 orang. Panelis memberikan penilaian terhadap aroma, rasa dan tekstur dari hard candy. Panelis yang digunakan dengan rentang umur (17-49 tahun) yang terdiri dari laki-laki sebanyak 47 orang dan perempuan sebanyak 53 orang. Dengan memberikan rentang penilaian $1-7$ dimana skala 1 (sangat tidak suka) sampai skala 7 (sangat suka) (Setyaningsih, 2010).

Hasil uji hedonik terhadap aroma diketahui bahwa formula III yang paling disukai dengan rata-rata 5,12, formula II dengan rata-rata 4,96 dan formula I dengan rata-rata 4,96. Dari analisis data kruskal wallis test bahwa jika nilai sig aroma 0.238 dimana nilai sig $>0,05$ kesimpulannya tidak ada perbedaan signifikan terhadap aroma pada tingkat kesukaan panelis. Aroma yang dihasilkan hard candy adalah aroma khasdari jeruk nipis, madu, dan kayu manis. Ketiga bahan tersebut diberikan dalam jumlah yang sama 
terhadap masing-masing formula sehingga tidak ada perbedaan signifikan (Nelwan, 2014).

Hasil uji hedonik terhadap rasa diketahui bahwa formula III yang paling disukai dengan rata-rata 6,24 , formula II dengan rata-rata 4,75 dan formula I dengan rata-rata 3,63. Dari analisis data kruskal wallis test bahwa jika nilai sig rasa 0.000 dimana nilai sig $<0,05$ kesimpulannya adalah ada perbedaan signifikan terhadap rasa pada tingkat kesukaan panelis. Penambahan sirup glukosa yang semakin tinggi mempengaruhi kualitas rasa manis hard candy sedangkan penambahan sirup glukosa yang rendah menyebab hard candy agak terasa asam karna adanya sari jeruk nipis (Merta, 2017).

Hasil uji hedonik terhadap tekstur diketahui bahwa formula III yang paling disukai dengan rata-rata 6,06 , formula II dengan rata-rata 5,46 dan formula I dengan rata-rat a 4,72. Dari analisis data kruskal wallis test bahwa jika nilai sig tekstur 0.000 dimana nilai sig $<0,05$ kesimpulannya adalah ada perbedaan signifikan terhadap tekstur pada tingkat kesukaan panelis. Sirup glukosa dalam pembuatan permen berfungsi untuk meningkatkan viskositas dari permen sehingga tidak lengket. Semakin banyak penambahan sirup glukosa maka semakin bagus tekstur permen yang dihasilkan karena tidak lengket (Rofiah dan Machfudz, 2014).

\section{KESIMPULAN}

Dari hasil penelitian yang telah dilakukan, dapat disimpulkan bahwa :

1. Dari semua formula permen dengan kombinasi sirup glukosa diketahui bahwauji fisik kadar air dan kadar abu permen memenuhi syarat SNI 3547.1:2008 tentang kembang gula keras.

2. Dari uji hedonik yang dilakukan diketahui bahwa ada pengaruh yang signifikan terhadap rasa dan tekstur dan tidak ada pengaruh yang signifikan terhadap aroma. Formula III yang paling banyak disukai dengan rata - rata nilai kesukaan untuk aroma 4,96, rasa 6,24 dan tekstur 6,06. Formula II dengan rata-rata untuk aroma 4,96, rasa 4,75, dan tekstur 5,46. Formula I dengan rata-rata kesukaan untuk aroma 5,12, rasa 3,63 dan tekstur 4,72. 


\section{DAFTAR PUSTAKA}

Apriani D, Gusnedi, Yenni D. (2013). Studi Tentang Nilai Viskositas Madu Hutan Dari Beberapa Daerah Di Sumatera Barat Untuk Mengetahui Kualitas Madu. Pillar of Physics, Vol 2: $91-98$.

Feringo T. (2019). Analisis kadar Air, Kadar abu, Kadar Abu Tak Larut Asam Dan Kadar Lemak Makanan Ringan Di Balai Riset Dan Standarisasi Industri Medan. Skripsi, Fakultas Farmasi Universitas Sumatera Utara.

Gebremariam, T., Brhane, G. (2014). Determination Of Quality And Adulteration Effects Of Honey From Adigrat And Its Surrounding Areas. International Journal Of Technology Enhancements And Emerging

Engineering Research, 2, 2347 4289.
Hamidi F, Raswen E dan Faizah H. (2016). Penambahan Sari Jeruk Nipis (Citrus aurantifolia) Terhadap Mutu Sirup Buah (Benincasahispida). Jom Faperta UR, Vol 3(2): 1-15.

Herdwiani W dan Endang SR. (2015). Uji Aktivitas Sitotoksik Ekstrak Kulit Batang Kayu Manis (Cinnamomum burmanni) Terhadap Kultur Sel $\mathrm{T}_{47} \mathrm{D}$. Jurnal Farmasi Indonesia, Vol $12(2): 102-113$.

Herdwiani W, dkk. (2009). Uji Keamanan Dan Uji Aktivitas Sitotoksik Minyak Kayu Manis (Cinnamomum burmanni). Indonesian Journal of Pharmaceutical Science and Technology, Vol 1(2):47 - 57.

Jay, J.M. 1996. Modern Food Microbiology. CBS Publishers, New Delhi, India.

Lauma SW, Damajanty HCP, Bernart SP . (2015). Uji Efektifitas Perasan Air Jeruk Nipis (Citrus aurantiolia S) Terhadap Pertumbuhan Bakteri 
Staphylococcus aureus secara

In Vitro. Pharmacon Jurnal

Ilmiah Farmasi, Vol 4 (4): 9 -

15.

Lawrence, DV. (1991). Food Flavoring. The AVI Publ : New York.

Mendei JH. (2014). Komposisi Beberapa Senyawa Gula Dalam Pembuatan Permen Keras Dari Buah Pala. Jurnal Penelitian Teknologi Industri, Vol 6(2) :110.

Merta CR. (2017). Pengaruh Kadar Gula Terhadap Kualitas Permen Jelli Belimbing Wuluh. Skripsi, Fakultas Pariwisata Universitas Negri Padang.

Nurwati. (2011) Formulasi Hard Candy dengan Penambahan Ekstrak Buah Jahe Merah (Sonneratia caseolaris) sebagai Flavor. Minithesis, Bogor, Institut Pertanian Bogor.

Nelwan, dkk. (2014). Pengaruh Konsentrasi Gelatin Dan Sirup Glukosa Terhadap Sifat Kimia Dan Sensoris Permen Jelly Sari
Buah Pala (Myristica fragrans Houtt). Jurnal Ilmu Dan Teknologi Pangan, Vol 10 (2):1-102

Pujilestari S dan Irnawati A. (2017). Mutu Permen Keras Dengan Konsentrasi Ekstrak Teh Hijau Yang Berbeda. Jurnal Konversi, Vol 6 (2):55-63.

Ramadhan. (2012). Pembuatan Permen Hard Candy yang Mengandung Propolis

Sebagai Permen Kesehatan

Gigi (Skripsi Publikasi).

Departemen Teknik

Kimia, Fakultas Teknik, Universitas Indonesia, Depok.

Rofiah dan Machfudz WDP. (2014). Kajian Dosis Sukrosa Dan Sirup Glukosa Terhadap Kualitas Permen Karamel Susu. Jurnal Nabatia, Vol 11 (1):5565.

Yumas M., (2012), Diversifikasi Manfaat Rimpang Temulawak Sebagai Komponen Aktif terhadap Bakteri Streptococcus mutans pada Pembuatan 
Permen Kesehatan. Jurnal Riset

Teknologi Industri, VI (11) 112.

Setyanigsih D. 2010. Analisis Sensori . Bogor : IPB Press.

Suranto A. 2004. Khasiat \& Manfaat Madu Herbal. Jakarta: Agro Media Pustaka. 